\title{
Self-Reported Adolescent Health Status of Extremely Low Birth Weight Children Born 1992-1995
}

WHAT'S KNOWN ON THIS SUBJECT: Previous cohorts of extremely low birth weight adolescents have assessed their health status similar to that of normal birth weight controls.

WHAT THIS STUDY ADDS: Extremely low birth weight adolescents born in the 1990s assess their health similar to controls but report less risk taking. Extremely low and normal birth weight children rate their health to be poorer at 8 than at 14 years.

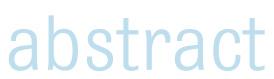

OBJECTIVES: To compare the self-reported health of extremely low birth weight (ELBW, $<1 \mathrm{~kg}$ ) adolescents with that of normal birth weight (NBW) controls and the children's assessments of their general health at ages 8 versus 14 years.

METHODS: One hundred sixty-eight ELBW children and 115 NBW controls of similar gender and sociodemographic status completed the Child Health and IIIness Profile-Adolescent Edition at age 14 years. It includes 6 domains: Satisfaction, Comfort, Resilience, Risk Avoidance, Achievement, and Disorders. At age 8 years, the children had completed the Child Health and IIIness Profile-Child Edition. Results were compared between ELBW and NBW subjects adjusting for gender and sociodemographic status.

RESULTS: ELBW adolescents rated their health similar to that of NBW adolescents in the domains of Satisfaction, Comfort, Resilience, Achievement and Disorders but reported more Risk Avoidance (effect size [ES] 0.6, $P<.001$ ). In the subdomain of Resilience, they also noted less physical activity (ES $-0.58, P<.001$ ), and in the subdomain of Disorders, more long-term surgical (ES -0.49) and psychosocial disorders (ES -0.49 ; both $P<.01$ ). Both ELBW and NBW children reported a decrease in general health between ages 8 and 14 years, which did not differ significantly between groups.

CONCLUSIONS: ELBW adolescents report similar health and well-being compared with NBW controls but greater risk avoidance. Both ELBW and NBW children rate their general health to be poorer at age 14 than at age 8 years, possibly due to age-related developmental changes. Pediatrics 2012;130:46-53
AUTHORS: Maureen Hack, MBChB, ${ }^{a}$ Mark Schluchter, PhD, ${ }^{b}$ Christopher B. Forrest, MD, PhD, ${ }^{c}$ H. Gerry Taylor, PhD, ${ }^{a}$ Dennis Drotar, PhD, ${ }^{d}$ Grayson Holmbeck, PhD, ${ }^{\text {e Eric }}$ Youngstrom, PhD, ${ }^{f}$ Seunghee Margevicius, MA, ${ }^{\mathrm{b}}$ and Laura Andreias, MD, MS

Departments of aPediatrics, and ${ }^{b}$ Epidemiology and Biostatistics, Case Western Reserve University, Cleveland, Ohio; 'Children's Hospital of Philadelphia, University of Pennsylvania School of Medicine, Philadelphia, Pennsylvania; ${ }^{d}$ Cincinnati Children's Hospital Medical Center, University of Cincinnati College of

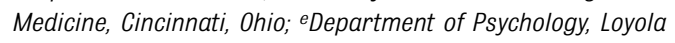
University, Chicago, Illinois; and ${ }^{f}$ Department of Psychology, University of North Carolina at Chapel Hill, Chapel Hill, North Carolina

KEY WORDS

preterm, self-reported health, adolescent, extremely low birth weight

\section{ABBREVIATIONS}

CHIP-AE-Child Health and IIIness Profile-Adolescent Edition CHIP-CE-Child Health and IIIness Profile-Child Edition $\mathrm{Cl}$-confidence interval

ELBW-extremely low birth weight

ES-effect size

NBW—normal birth weight

SES—sociodemographic status

Dr Hack supervised the study and had full access to all of the data in the study and takes responsibility for the integrity of the data and the accuracy of the data analysis; Drs Hack, Taylor, Forrest, Drotar, Schluchter, Holmbeck, and Youngstrom developed the study concept and design; Drs Hack and Andreias acquired the data; Drs Hack, Schluchter, Taylor, Andreias, Margevicius, and Forrest participated in the analysis, including statistical analysis and interpretation of the data; Dr Hack drafted the first version of the manuscript; and all the coauthors participated in the critical revision of the manuscript and approved its submission for publication

www.pediatrics.org/cgi/doi/10.1542/peds.2011-3402

doi:10.1542/peds.2011-3402

Accepted for publication Mar 8, 2012

Address correspondence to Dr Maureen Hack, Rainbow Babies and Children's Hospital, University Hospitals of Cleveland Case Medical Center, 11100 Euclid Ave, Cleveland, OH 44106-6010. E-mail:mxh7@case.edu

PEDIATRICS (ISSN Numbers: Print, 0031-4005; Online, 1098-4275) Copyright (C) 2012 by the American Academy of Pediatrics FINANCIAL DISCLOSURE: The authors have indicated they have no financial relationships relevant to this article to disclose.

FUNDING: Supported by grants R01 HD 39756, M01 RR000, and ULI RR024989 from the National Institute of Health. Funded by the National Institutes of Health $(\mathrm{NIH})$. 
The increased survival of preterm children has led to an interest in their longterm outcomes over and above those pertaining to neurosensory and cognitive sequelae. ${ }^{1}$ During childhood and adolescence, in addition to objective measures of health, subjective physical, psychological, and social aspects of health become important measures. ${ }^{2}$ We recently reported on the self-perceived health and well-being at age 8 years of extremely low birth weight children (ELBW; <1 kg) born in 1992-1995 compared with normal birth weight (NBW) controls and the children's perspective of their health compared with that of their parents. ${ }^{3}$ Despite higher rates of chronic conditions, 8-year-old ELBW children rated their health similar to controls, whereas their parents reported poorer health for their children compared with parents of controls. Physical, emotional, and social developmental changes during adolescence may have important effects on health. These may be associated with declines in certain aspects of health (eg, physical activity and family connectedness), whereas other aspects of health may become stronger (eg, peer relations). We thus sought to examine the perspective of the health and well-being of the ELBW children at age 14 years compared with NBW controls and compared general health to reports at 8 years. Based on our findings at 8 years 3 and on self-reports of preterm adolescents born in the 1980s, ${ }^{4-6}$ we hypothesized that the self-perception of health of ELBW children born in the 1990s would not differ from that of their NBW peers; that their self-perception of health would be related to both biomedical and sociodemographic factors, and that the children would rate their general health worse at age 14 than at age 8 years. ${ }^{3}$

\section{METHODS}

\section{ELBW Cohort}

The population included survivors of a cohort of 344 ELBW children admitted to the NICU at Rainbow Babies and Children's Hospital, Cleveland, Ohio, during 1992-1995. Thirteen children, including 10 with major malformations, 2 with AIDS, and 1 with tuberous sclerosis, were excluded. Of the remaining 331 children, 238 (72\%) survived, of whom 219 (92\%) were followed to 8 years and $181(76 \%)$ to 14 years. At this time, 168 (71\%) completed the Child Health and IIIness Profile-Adolescent Edition (CHIP-AE) questionnaire. ${ }^{7}$ The 13 children who did not complete the questionnaire, compared with the 168 children who did, included more boys (10 [77\%] vs 60 [36\%]) and significantly higher rates of neurosensory impairments (8 [62\%] vs 23 [14\%]) and subnormal $(<70)$ IQ (12 [92\%] vs 20 [12\%]). ${ }^{8}$ Similarly, the surviving birth cohort of 70 children who did not complete the questionnaire, included more boys (41 [59\%] vs 60 [36\%]) but did not differ in sociodemographic descriptors (socioeconomic status [SES]), birth weight, gestational age, or rates of neonatal cerebral ultrasound abnormality. At age 8 years, 202 children had completed the Child Health and IIIness ProfileChild Edition (CHIP-CE). ${ }^{9}$ The 168 children who completed the CHIP-AE at age 14 did not differ in SES, birth data, gender, or rates of subnormal IQ (13 [8\%] vs 3 [9\%]) from the 34 children who did not complete the CHIP-AE.

\section{Comparison Group of NBW Children}

An NBW group of 176 children born at term gestation ( $>36$ weeks) was recruited at age 8 years from the same schools as the ELBW children and of the same gender, race, and age within 3 months. Of these children, 115 (65\%) were followed to age 14 years, all of whom completed the CHIPAE questionnaire. They did not differ from the 61 children not followed in maternal SES, gender, or subnormal 8-year IQ.

\section{Study Protocol}

At 14 years, the primary caregiver, usually the mother, was interviewed concerning the child's health. The child was interviewed and underwent psychometric testing. ${ }^{10}$

The primary outcome measure of this report, the CHIP-AE, is a multidimensional adolescent self-report instrument developed for children aged 11 to 21 years. It includes 150 items related to perceived health, functioning, and well-being and 46 disease- or injury-specific questions. ${ }^{7}$ The most common recall period is the past 4 weeks. The questions are organized into 20 subdomains and 6 conceptually based domains (Table 1): (1) Satisfaction, which includes items concerning self-worth and satisfaction with one's health; (2) Comfort, which includes physically and emotionally experienced feelings and limitations in activity; (3) Resilience, which includes states and behaviors that promote health, including social problem solving, physical activity, home safety, and health and family involvement; (4) Risk avoidance, which includes avoidance of individual risks, behaviors that may disrupt social development and subsequent health, and influences of peers who are involved in risky behaviors; (5) Achievement, which includes both academic achievement in school and work performance; and (6) Disorders, which include biomedically defined states of ill health, injuries, and impairments. Seventy percent of items had to be completed for domain and subdomain scores to be calculated. Higher scores indicate better health and well-being. All the domains have internal consistency reliability of $\geq 0.70$ and 1 -week test-retest reliability of $>0.60$. The CHIP-AE has moderate to high correlations with other measures that assess single domains of health and can discriminate "well" respondents from those with "illness" such as asthma and other chronic conditions. ${ }^{11,12}$ The questionnaire is self-administered and takes 20 minutes to complete. If a child had difficulty reading or understanding specific 
TABLE 1 Description of CHIP-AE Domains and Subdomains

\begin{tabular}{|c|c|c|}
\hline Domain and Subdomains & Description & Examples of Questions \\
\hline I. Satisfaction: & Overall evaluations of health and well-being & \\
\hline 1. Satisfaction with health & Overall perceptions of and beliefs about one's health & Full of energy \\
\hline 2. Self-esteem & Self-worth & Like being the way I am \\
\hline II. Comfort: & $\begin{array}{l}\text { Specific physical and emotional sensations/ feelings that } \\
\text { interfere with comfort }\end{array}$ & \\
\hline 1. Physical comfort & Physical feelings and symptoms & Days free of pain \\
\hline 2. Emotional comfort & Emotional feelings and symptoms & Days had trouble falling asleep \\
\hline 3. Physical activity & Restrictions in age-appropriate activities and limitations in mobility & Days had trouble walking \\
\hline III. Resilience: & $\begin{array}{l}\text { States and behaviors known to protect individuals from } \\
\text { subsequent illness or injury }\end{array}$ & \\
\hline 1. Physical activity & Involvement in a variety of activities related to fitness & Days played hard enough to sweat \\
\hline 2. Home safety and health & Aspects of the home that reduce/increase likelihood of harm & Such as smoke detectors \\
\hline 3. Family involvement & $\begin{array}{l}\text { The amount and type of activities done as a family } \\
\text { and family support available }\end{array}$ & Days family spent time with you \\
\hline 4. Social problem solving & Active approaches to solving a hypothetical problem & Try to see good side \\
\hline IV. Achievement: & $\begin{array}{l}\text { Evaluation of one's own developmentally appropriate role } \\
\text { performance }\end{array}$ & \\
\hline 1. Academic performance & Perceived school accomplishments & Received a school award or prize \\
\hline 2. Work performance & Perceived work accomplishments & Days not at work on time \\
\hline V. Risk avoidance: & $\begin{array}{l}\text { States and behaviors that are known to heighten } \\
\text { the likelihood of subsequent illness or injury }\end{array}$ & \\
\hline 1. Individual risks & Activities which threaten individual development & Last time smoked cigarettes \\
\hline 2. Threats to achievement & Negative behaviors that threaten to disrupt social development & Last time carried a weapon \\
\hline 3. Peer influences & Involvement with peers who engage in risky behaviors & Number of friends who smoke marijuana \\
\hline VI. Disorders: & Diagnostic entities including conditions, injuries, and impairments & \\
\hline 1. Acute minor disorders & eg, colds, tonsillitis, sprains, etc & In past $12 \mathrm{mo}$ \\
\hline 2. Acute major disorders & eg, pneumonia, broken bones, hepatitis, etc & Ever had problems? If so, in past $12 \mathrm{mo}$ ? \\
\hline 3. Recurrent disorders & eg, ear infections, asthma, allergies, etc & \\
\hline 4. Long-term medical disorders & eg, arthritis, diabetes, epilepsy, etc & \\
\hline 5. Long-term surgical disorders & eg, scoliosis, vision problems, hearing problems, etc & \\
\hline 6. Psychosocial disorders & eg, speech problems, eating problem, learning disability & \\
\hline
\end{tabular}

questions, the research assistant would help by reading or explaining them. At 8 years, the children completed the CHIP$\mathrm{CE}$, a conceptually similar instrument based on the CHIP-AE ${ }^{3,9}$ and underwent IQ testing and neurologic, vision, and hearing testing. ${ }^{8}$

The study was approved by the Institutional Review Board of University Hospitals of Cleveland, Case Medical Center, and written informed consent provided by parents with signed assent provided by their children.

\section{DATA ANALYSIS}

Univariate comparisons between the ELBW and NBW groups were made with the use of the Student's $t$ test for continuous variables and the $\chi^{2}$ test or Fisher's exact test for discrete variables. We also examined outcomes after excluding subjects with neurosensory impairments. Domain and subdomain scores of the VLBW and NBW subjects were compared and effect sizes (calculated as the mean difference between VLBW and NBW scores, adjusted for SES, race, and gender, divided by the SD of the NBW group). Because of the known effects of SES and gender on health and behavior, we controlled for these factors in all analyses. In additional multivariable analyses adjusting for birth weight status (ELBW versus NBW) and SES, we considered the separate effects of neurosensory impairment and the 8-year CHIP-CE scores. Sample sizes of 168 ELBW and 115 NBW children provided $80 \%$ power to detect effect sizes of 42 between groups using a 2-sided ttest with significance level of .01 and $80 \%$ power to detect differences in binary proportions of $2 \%$ vs $13 \%, 5 \%$ vs $19 \%, 10 \%$ vs $26 \%$, or $15 \%$ vs $33 \%$, by using a $\chi^{2}$ test.
Although the CHIP-CE and CHIP-AE are conceptually similar, their format, wording, and number of items differ, mainly because of developmental appropriateness. Even for questions that are similar, the majority of responses in the CHIP-CE range from "never" to "always" on a 5-point Likert scale, whereas CHIP-AE responses range from "no days" to "15-28 days" on a 4-point scale. We thus used the only question with identical wording and format at both ages to examine changes in health perception between ages 8 and 14 years. This concerns general health with Likert responses ranging from excellent (5), to very good (4), good (3), fair (2), and poor (1), Paired $t$ tests were used to compare the mean score of this question between ages 8 and 14 years for ELBW and NBW children separately. Multiple linear regression analysis compared the changes in general health between the 
ELBW and NBW groups, adjusting for SES, race, and gender.

SES was defined as a mean of the sample $z$-scores of years of maternal education and median family income according to the 2000 Census tract of the family's neighborhood. SPSS version 19 (SPSS Inc, Chicago, IL) and SAS version 9.2 (SAS Institute, Inc, Cary, NC) were used for the analyses. Two-sided $t$ tests were used with a value of $P<.01$ considered statistically significant to account for multiple comparisons.

\section{RESULTS}

Demographic, Birth Data, and 14-Year Outcomes

Maternal sociodemographic descriptors between the ELBW and NBW children did not differ significantly (Table 2). Twentythree ELBW children had neurosensory impairments. Significantly more ELBW than NBW adolescents were enrolled in Individualized Education Programs and received Supplemental Security Income.

\section{Comparison of the Mean CHIP-AE Domain and Subdomain Scores Between ELBW and NBW Children}

ELBW children did not differ significantly from NBW children in the domains of Satisfaction, Comfort, Resilience, Achievement, or Disorders. However, they had significantly higher scores in the domain of Risk avoidance (ie, fewer risk behaviors) than NBW children (effect size [ES] 0.60) (Table 3). The findings were similar after excluding children with neurosensory disorders (data not shown). The greater risk avoidance among the ELBW children pertained to all 3 subdomains of risk (all $P<.001$ ). of the individual risks, fewer ELBW children reported alcohol and marijuana use, although these differences were not considered significant at $P<$ .01). Thirty-two (18\%) ELBW vs 31 (27\%) NBW children reported ever drinking beer or wine $(P=.013)$ and $3(2 \%)$ vs

TABLE 2 Maternal Demographic Risk Factors, Perinatal Data, and 14-Year Outcomes

\begin{tabular}{|c|c|c|}
\hline & ELBW $n=168$ & NBW $n=115$ \\
\hline \multicolumn{3}{|l|}{ Maternal demographic data ${ }^{a}$} \\
\hline Age, $y^{b}$ & $43 \pm 6$ & $41 \pm 6$ \\
\hline Married, $n$ & $73(44 \%)$ & $63(55 \%)$ \\
\hline \multicolumn{3}{|l|}{ Education, $n$} \\
\hline$<$ High school & $13(8 \%)$ & $12(10 \%)$ \\
\hline High schoolc & $51(30 \%)$ & $22(19 \%)$ \\
\hline$>$ High school & $104(62 \%)$ & $81(70 \%)$ \\
\hline \multicolumn{3}{|l|}{ Race, $n$} \\
\hline Whited & $66(39 \%)$ & $39(34 \%)$ \\
\hline Black & $102(61 \%)$ & $76(66 \%)$ \\
\hline Mean percent below poverty levele & $13 \pm 13$ & $15 \pm 13$ \\
\hline Mean family income, $\$ \pm S D^{f}$ & $44.5 \pm 19$ & $40.2 \pm 19$ \\
\hline \multicolumn{3}{|l|}{ Perinatal data } \\
\hline Birth weight, g \pm SD & $813 \pm 122$ & $3260 \pm 524$ \\
\hline Gestational age, wk \pm SD & $26.4 \pm 2$ & $\geq 37$ \\
\hline Female gender, $n$ & $108(64 \%)$ & $73(64 \%)$ \\
\hline Multiple birth, $n$ & $28(17 \%)$ & 0 \\
\hline \multicolumn{3}{|l|}{ 14-y Data } \\
\hline Age, y $\pm S D$ & $14: 74 \pm 0.67$ & $14: 80 \pm 0.75$ \\
\hline Neurosensory impairment, $n^{\S}$ & $23(14 \%)$ & 0 \\
\hline IQ $<70, n$ & $20(12 \%)$ & $4(4 \%)$ \\
\hline Individualized Education Program, $n$ & $75(45 \%)$ & $11(10 \%)^{\star \star}$ \\
\hline $\begin{array}{l}\text { Children receiving Supplemental } \\
\text { Security Income, } n\end{array}$ & 32 (19\%) & $7(6 \%)^{\star}$ \\
\hline $\begin{array}{l}\text { a Unless otherwise stated, refers to primary } \\
\text { the biologic or adoptive mother. } \\
{ }^{\mathrm{b}} \text { Biologic mothers only. } \\
{ }^{\mathrm{c}} \text { Includes GED. } \\
{ }^{\mathrm{d}} \text { Includes } 1 \text { Asian ELBW mother. } \\
\text { e Mean percent of families below the poverty le } \\
{ }^{\mathrm{f}} \text { Mean of median family income in } 1000 \text { s of } \\
{ }^{\mathrm{g}} \text { Includes } 19 \text { children with cerebral palsy, } 1 \\
{ }^{\star} P<.01,{ }^{\star \star} P<.001 \text {. }\end{array}$ & $\begin{array}{l}000 \text { Census tract ne } \\
\text { רe } 2000 \text { Census tr } \\
\text { with deafness. }\end{array}$ & he families lived. \\
\hline
\end{tabular}

10 (12\%), respectively, ever using marijuana $(P=.030)$. Neither group admitted to ever using cocaine or crack. Fewer ELBW than NBW children reported ever having sexual intercourse (18 [11\%] vs 29 [25\%], $P<.001)$. There was no difference between groups in ever smoking (11 [7\%] ELBW vs 11 [10\%] NBW). Of the Threats to achievement, significantly fewer ELBW than NBW children reported ever driving a car, doing something risky or dangerous on a dare, breaking parental rules, or having trouble getting along with teachers. Of the Peer influences, significantly fewer ELBW than NBW children reported having friends who smoked, drank alcohol, used marijuana, or had sexual intercourse.

The domain of Resilience did not differ significantly between ELBW and NBW children. However, ELBW children had significantly lower scores in the subdomain of Physical activity (ES - 0.58) (ie, less physical activity). There were no differences between groups in the Disorders domain, but at the subdomain level, ELBW children reported significantly more Long-term Surgical disorders (ES -0.49). ELBW children also had lower scores in the subdomain of Psychosocial disorders (ES - 0.49), mainly due to being told by a physician that they had a learning disability (36 [21\%] ELBW vs 107 [7\%] NBW children, $P=.003)$.

\section{Significant Correlates of the} Domains and Subdomains of Health In the multivariable analyses, the Risk avoidance domain was significantly associated with birth weight status (ELBW versus NBW, $\beta=.19$, 95\% confidence interval $[\mathrm{Cl}] .13-.26$, and white race, 


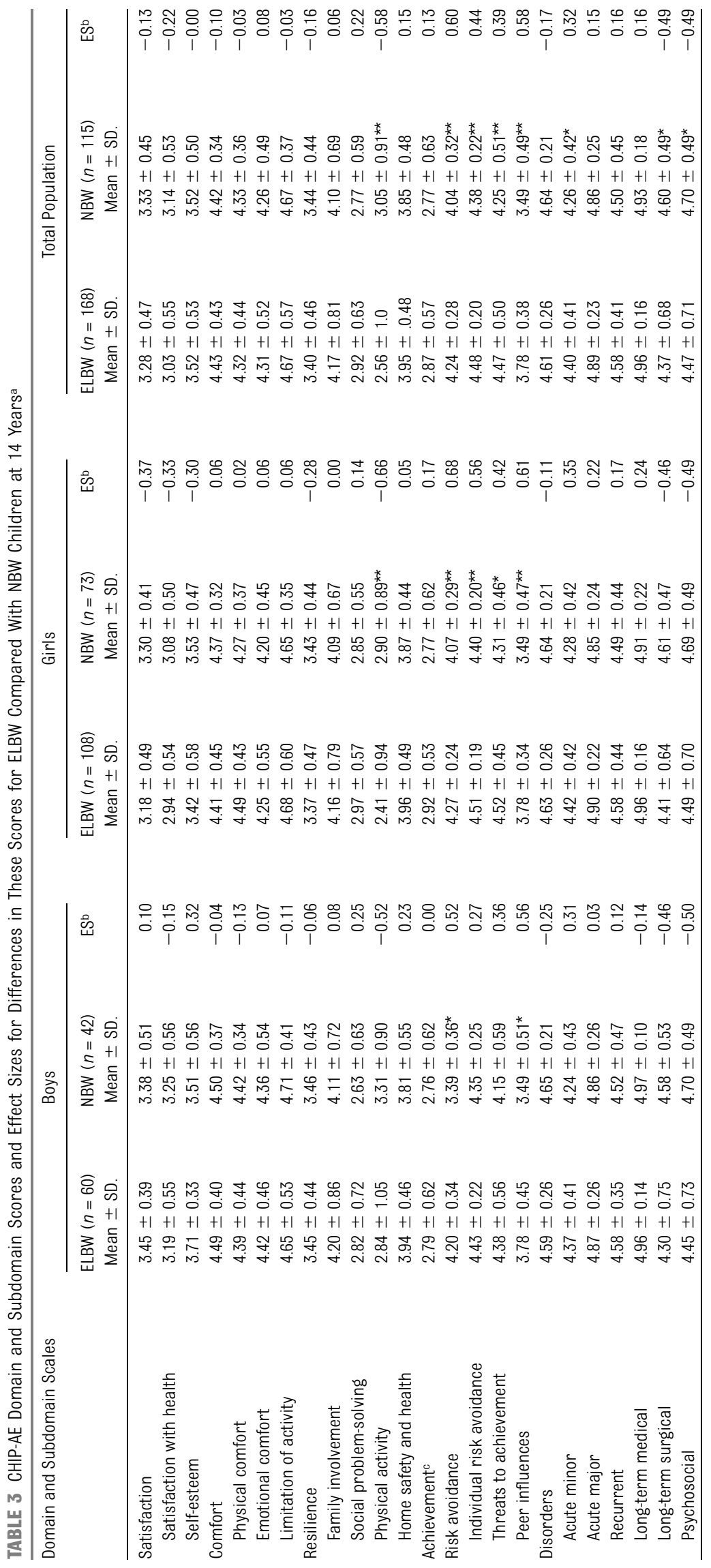

$\beta=.17,95 \% \mathrm{Cl}$.09-.25). Significant correlates of decreased Physical activity included lower SES $(\beta=-.20$, $95 \% \mathrm{Cl}-.34$ to -.07 ), female gender $(\beta=-.45,95 \% \mathrm{Cl}-.66$ to -.23$)$, and neurosensory impairment $(\beta=-.95$, $95 \% \mathrm{Cl}-1.34$ to -.56 ). Long-term Surgical Disorders were associated with neurosensory impairment $(\beta=-.63$, $95 \% \mathrm{Cl}-.90$ to -.36 ). In the domains of health that did not differ between ELBW and NBW children, higher SES was significantly associated with better Resilience. Female gender was associated with poorer Satisfaction and less Comfort, and white race was associated with more Comfort and more Resilience (data not shown).

Examination of the association between domains of the 8-year CHIP-CE to the respective domains of the 14-year CHIP$A E$, controlling for race, gender, and SES, revealed a significant partial correlation coefficients for Comfort ( $r=0.233$, $P<.001$ ) but not for any of the other domains of health

\section{Comparison of 8-Year With 14-Year Assessment of General Health Status}

The mean score for the question rating general health did not differ significantly between ELBW and NBW children at either age 8 or 14 years (Table 4). Both groups rated their health significantly poorer at 14 than at 8 years. Multiple linear regression analysis adjusting for race, gender, and SES revealed that these changes did not differ significantly between the ELBW and NBW children in analyses of both genders combined ( $\beta=-.14,95 \% \mathrm{Cl} .19$ to -.47 ) or in gender-specific analyses.

\section{DISCUSSION}

We sought to examine the self-perception of health and well-being of adolescent ELBW children born in the 1990s compared with NBW controls according to a multidimensional questionnaire, the 
TABLE 4 General Health at Age 8 and 14 Years

\begin{tabular}{|c|c|c|c|c|c|c|}
\hline \multirow[t]{2}{*}{ General Health, mean score \pm SD } & \multicolumn{3}{|c|}{ ELBW } & \multicolumn{3}{|c|}{ NBW } \\
\hline & Age 8 y & Age 14 y & Mean Difference $(95 \% \mathrm{Cl})^{\mathrm{a}}$ & Age 8 y & Age 14 y & Mean Difference $(95 \% \mathrm{Cl})^{\text {a }}$ \\
\hline \multirow{2}{*}{ Total population } & \multicolumn{2}{|c|}{$n=167^{b}$} & \multicolumn{4}{|c|}{$n=115$} \\
\hline & $4.34 \pm 1.03^{c}$ & $3.85 \pm 0.92^{\mathrm{c}}$ & $-0.49(-0.71 \text { to }-0.28)^{\star \star}$ & $4.30 \pm 0.94^{c}$ & $3.91 \pm 0.89^{c}$ & $-0.38(-0.61 \text { to }-0.15)^{\star}$ \\
\hline \multirow[t]{2}{*}{ Boys } & \multicolumn{2}{|c|}{$n=60$} & \multicolumn{4}{|c|}{$n=42$} \\
\hline & $4.45 \pm 0.96$ & $3.93 \pm 0.90$ & $-0.52(-0.85 \text { to }-0.18)^{*}$ & $4.40 \pm 0.86$ & $4.12 \pm 0.90$ & $-0.29(-0.65$ to 0.07$)$ \\
\hline \multirow[t]{2}{*}{ Girls } & \multicolumn{2}{|c|}{$n=107^{\mathrm{b}}$} & \multicolumn{4}{|c|}{$n=73$} \\
\hline & $4.27 \pm 1.06$ & $3.80 \pm 0.94$ & $-0.48(0.76 \text { to }-0.20)^{*}$ & $4.23 \pm 0.98$ & $3.79 \pm 0.88$ & $-0.44(-0.74 \text { to }-0.14)^{*}$ \\
\hline
\end{tabular}

Results are unadjusted. Higher score indicates better health.

a Paired $t$ test. Mean difference calculated as 8 y minus 14 y score.

b One girl response is missing at age $8 \mathrm{y}$.

${ }^{c}$ General health scores of the ELBW versus NBW children did not differ significantly at 8 or $14 \mathrm{y}(P=.78$ and .49 , respectively, after adjusting for SES, race, and gender ${ }^{\star} P<.01,{ }^{\star \star} P<.001$

CHIP-AE.7 The major difference pertained to the Risk avoidance domain with ELBW children reporting significantly more risk avoidance, ie, less risk taking, than NBW controls. This included fewer individual risks, fewer threats to achievement and fewer relationships with delinquent peers. There were no differences between groups in the domains of Satisfaction, Comfort, Resilience, or Disorders, although examination of the subdomains revealed significantly less physical activity and more long-term surgical and psychosocial disorders compared with their peers. Both ELBW and NBW children reported a decrease in general health between age 8 and 14 years, which did not differ between groups.

Our results are in agreement with reports of ELBW adolescents and young adults born before the 1990s who, in general, considered their health and well-being to be similar to that of their peers, despite higher rates of chronic medical and neurodevelopmental problems. ${ }^{4-6,13}$

The rates of general health and risk taking among our NBW subjects are in the range of normative populations. Sixty nine percent of our NBW adolescents reported their health to be very good or excellent, similar to a normative prevalence of $63 \% .^{14}$ In a predominantly urban black population aged 14 years, lifetime rates of wine or beer use were $26 \%$; of marijuana, $7 \%$; and of smoking, $13 \% .{ }^{15}$ In 2008, nationally in the United States, rates higher than ours were reported among children in the eighth grade, with lifetime use of any alcohol, $38.9 \%$; cigarette use, $20.5 \%$; and marijuana use, $14.6 \% .^{16}$

With the exception of the increased risk avoidance reported by the ELBW children at 14 years, our current findings are similar to those we reported for the same population at 8 years. ${ }^{3}$ However, the potential types of risk taking behavior change during the transition from childhood to adolescence. At 8 years. they include "getting into trouble at school" and "picking on, or threatening to hurt other children." 9 At 14 years. they include individual risks such as alcohol use and sexual activities. ${ }^{7}$

The findings of less risk taking among the ELBW adolescents are in agreement with reports of preterm young adults, which include less risk taking, delinquent behavior, and association with delinquent peers. ${ }^{17-21}$ The reasons for less risk taking are not fully understood but may include emotional problems. In normative populations, children with learning disabilities 22 or chronic conditions are more, rather than less, likely to smoke and use marijuana. ${ }^{23}$ We previously reported an increase in parent protection at age 8 years. ${ }^{24}$ Relative social isolation of children with disabilities and increased parental supervision may be associated with diminished opportunities for risk taking. ${ }^{25,26}$ However, our findings of decreased risk taking among the ELBW children were evident even after excluding the children with neurosensory impairments.

Global assessment of health is considered to be a good predictor of mortality and morbidity in adults. ${ }^{27,28} \mathrm{~A}$ decrease in self-reported health between childhood and adolescence has previously been reported in normative populations, although, contrary to our findings, others note a greater decline for girls than boys. ${ }^{29-31}$ The decrease in our ELBW and NBW populations cannot be explained by changes in rates of chronic conditions, which remained fairly stable. ${ }^{32}$ It could possibly be due to adolescent changes in expectations and priorities of life and to social influences of peers. ${ }^{33}$

Resilience has been defined in preterm studies as optimal cognitive, behavior health, and growth. ${ }^{34,35}$ In the CHIP-AE, however, "resilience" pertains to states and behaviors that promote health. The decreased physical activity reported by our ELBW adolescents has previously been reported for preterm young adults $^{36,37}$ and is considered to be related to poorer motor performance 38 and reduced exercise capacity. ${ }^{39}$ Correlates of decreased physical activity in our population included SES, female gender, and neurosensory impairment. The relationship of SES to physical activity and health includes community 
resources, health care, and differences in family lifestyle. ${ }^{40-42}$

One possible limitation to our study is that there may be inaccuracy in the reporting of physical activities and risk taking. ${ }^{16,43}$ The reliability of selfreporting of sexual behavior is also questionable. ${ }^{44}$ Current health may also influence the reporting of health status. ${ }^{45}$ We had a greater loss to follow-up of males and children with neurologic impairments, which may influence the results. Children with neurologic impairments could potentially rate their health worse than do less-impaired children. Our results revealed a significant association between female gender and poorer satisfaction with health, less comfort, and less physical activity (ie, less exercise). Had more males been included in the study, the scores of satisfaction with health, comfort, and physical activity might have been higher (ie, better health status). However, because we documented a negative association between neurologic

\section{REFERENCES}

1. Saigal S, Rosenbaum P. What matters in the Iong term: reflections on the context of adult outcomes versus detailed measures in childhood. Semin Fetal Neonatal Med. 2007;12(5):415-422

2. Topolski TD, Edwards TC, Patrick DL. Toward youth self-report of health and quality of life in population monitoring. Ambul Pediatr. 2004;4(4 suppl):387-394

3. Hack M, Forrest CB, Schluchter M, et al. Health status of extremely low-birth-weight children at 8 years of age: child and parent perspective. Arch Pediatr Adolesc Med. 2011;165(10):922-927

4. Gray R, Petrou S, Hockley C, Gardner F. Selfreported health status and health-related quality of life of teenagers who were born before 29 weeks' gestational age. Pediatrics. 2007;120(1). Available at: www.pediatrics. org/cgi/content/full/120/1/e86

5. Indredavik MS, Vik T, Heyerdahl S, Romundstad P, Brubakk A-M. Low-birthweight adolescents: quality of life and parent-child relations. Acta Paediatr. 2005;94(9):1295-1302 impairment and physical activity, inclusion of more neurologically impaired children among the participants might potentially neutralize this effect. Our results are based on self-reports by the youth with no information from parents. Parents tend to report poorer health for their preterm children than the children themselves. ${ }^{3,5,6}$ In contrast among normative populations, adolescents tend to be less optimistic about their health than are their parents. ${ }^{46,47}$

Strengths of our study include the longitudinal design, the relatively good follow-up rate, that the children were followed longitudinally, and that the CHIP-AE provides a comprehensive assessment of health status with components of the broader concept of health advocated by the World Health Organization. ${ }^{48}$

Although the ELBW subjects consider their health status to be similar to that of their peers, their persisting high rates of chronic illnesses that we recently reported, including asthma and obesity, together with their decreased physical activity, may not bode well for their future adult health. ${ }^{32}$ Furthermore, although their greater risk avoidance may be considered an advantage, this may not be a beneficial characteristic during adolescence. ${ }^{49,50}$ Ongoing surveillance of medical and behavioral health of ELBW adolescents, together with encouragement of a healthy life style, will be necessary to ensure a successful transition to adulthood. ${ }^{51}$

\section{ACKNOWLEDGMENTS}

We thank Ms Kathy Winter, who coordinated the project and participated in the interview of the parents; Mrs Ellen Durand MA and Mrs Heather Marcinick MA, research assistants, who tested the children and administered the questionnaires; Ms Sheree Hemphill MS, who developed the REDCap database; Mrs Lydia Cartar MA, who participated in the initial data management and analysis; and Mrs Bonnie Tarantino BA and Mr Alpher Torres, who provided clerical assistance.
6. Saigal S, Feeny D, Rosenbaum P, Furlong W, Burrows E, Stoskopf B. Self-perceived health status and health-related quality of life of extremely low-birth-weight infants at adolescence. JAMA. 1996;276(6):453-459

7. Starfield B, Riley AW, Green BF, et al. The adolescent child health and illness profile. A population-based measure of health. Med Care. 1995;33(5):553-566

8. Kaufman A, Applegate B. Short forms of K-ABC Mental Processing and Achievement Scales at age 4 to 12-1/2 years for clinical and screening purposes. J Clin Child Psychol. 1988;17:359-369

9. Riley AW, Forrest CB, Rebok GW, et al. The Child Report form of the CHIP-Child Edition: reliability and validity. Med Care. 2004;42 (3):221-231

10. Psychological Corporation. Wechsler Abbreviated Scale of Intelligence (WASI). San Antonio, TX: Psychological Corporation; 1999

11. Starfield B, Forrest CB, Ryan SA, Riley AW, Ensminger ME, Green BF. Health status of well vs ill adolescents. Arch Pediatr Adolesc Med. 1996;150(12):1249-1256

12. Forrest CB, Starfield B, Riley AW, Kang M. The impact of asthma on the health status of adolescents. Pediatrics. 1997;99(2):E1

13. Zwicker JG, Harris SR. Quality of life of formerly preterm and very low birth weight infants from preschool age to adulthood: a systematic review. Pediatrics. 2008;121(2). Available at: www.pediatrics.org/cgi/content/ full/121/2/e366

14. Johnson SB, Wang C. Why do adolescents say they are less healthy than their parents think they are? The importance of mental health varies by social class in a nationally representative sample. Pediatrics. 2008;121 (2). Available at: www.pediatrics.org/cgi/ content/full/121/2/e307

15. Delaney-Black V, Chiodo LM, Hannigan JH, et al. Just say "I don't": lack of concordance between teen report and biological measures of drug use. Pediatrics. 2010;126(5):887-893

16. Johnston LD, O'Malley PM, Bachman JG, Schulenberg JE. Monitoring the Future 
National Results on Adolescent Drug Use: Overview of Key Findings. Bethesda, MD: National Institute on Drug Abuse; 2008. NIH Publication No. 09-7401

17. Hack M, Flannery DJ, Schluchter M, Cartar L, Borawski E, Klein N. Outcomes in young adulthood for very-low-birth-weight infants. N Engl J Med. 2002;346(3):149-157

18. Cooke RW. Health, lifestyle, and quality of life for young adults born very preterm. Arch Dis Child. 2004;89(3):201-206

19. Lindström K, Lindblad F, Hjern A. Psychiatric morbidity in adolescents and young adults born preterm: a Swedish national cohort study. Pediatrics. 2009;123(1). Available at: www.pediatrics.org/cgi/content/full/123/1/e47

20. Strang-Karlsson S, Räikkönen $K$, Pesonen $A K$, et al. Very low birth weight and behavioral symptoms of attention deficit hyperactivity disorder in young adulthood: the Helsinki study of very-low-birth-weight adults. Am J Psychiatry. 2008;165(10):13451353

21. Hille ET, Dorrepaal C, Perenboom R, Gravenhorst JB, Brand R, Verloove-Vanhorick SP; Dutch POPS-19 Collaborative Study Group. Social lifestyle, risk-taking behavior, and psychopathology in young adults born very preterm or with a very low birthweight. J Pediatr. 2008;152(6):793-800, 800, e1-e4

22. Maag JW, Irvin DM, Reid R, Vasa SF. Prevalence and predictors of substance use: a comparison between adolescents with and without learning disabilities. J Learn Disabil. 1994;27 (4):223-234

23. Surís J-C, Michaud P-A, Akre C, Sawyer SM. Health risk behaviors in adolescents with chronic conditions. Pediatrics. 2008;122(5). Available at: www.pediatrics.org/cgi/content/ full/122/5/e1113

24. Wightman A, Schluchter M, Drotar D, et al. Parental protection of extremely low birth weight children at age 8 years. J Dev Behav Pediatr. 2007;28(4):317-326

25. Blum RW, Kelly A, Ireland M. Health-risk behaviors and protective factors among adolescents with mobility impairments and learning and emotional disabilities. J Adolesc Health. 2001;28(6):481-490

26. Stevens SE, Steele CA, Jutai JW, Kalnins IV, Bortolussi JA, Biggar WD. Adolescents with physical disabilities: some psychosocial aspects of health. J Adolesc Health. 1996;19 (2):157-164

27. Case A, Fertig A, Paxson C. The lasting impact of childhood health and circumstance. $\checkmark$ Health Econ. 2005;24(2):365-389
28. Idler EL, Russell LB, Davis D. Survival, functional limitations, and self-rated health in the NHANES I Epidemiological Follow-up Study, 1992. Am J Epidemiol. 2000;152:874883

29. Michel G, Bisegger C, Fuhr DC, Abel T; KIDSCREEN group. Age and gender differences in health-related quality of life of children and adolescents in Europe: a multilevel analysis. Qual Life Res. 2009;18(9): $1147-1157$

30. Palacio-Vieira JA, Villalonga-Olives E, Valderas $\mathrm{JM}$, et al. Changes in health-related quality of life (HRQOL) in a population-based sample of children and adolescents after 3 years of follow-up. Qual Life Res. 2008;17 (10): 1207-1215

31. Simon AE, Chan KS, Forrest CB. Assessment of children's health-related quality of life in the United States with a multidimensional index. Pediatrics. 2008;121(1). Available at: www.pediatrics.org/cgi/content/full/121/1/ e118

32. Hack M, Schluchter M, Andreias L, et al. Change in prevalence of chronic conditions between childhood and adolescence among extremely low-birth-weight children. JAMA. 2011;306(4):394-401

33. Drotar D, ed. Measuring Health-Related Quality of Life in Children and Adolescents. In: Mahwah, NJ: Lawrence Erlbaum Associates; 1998

34. Bradley RH, Whiteside L, Mundfrom DJ, Casey PH, Kelleher KJ, Pope SK. Early indications of resilience and their relation to experiences in the home environments of low birthweight, premature children living in poverty. Child Dev. 1994;65(2 Spec No): 346-360

35. Msall ME. Optimizing early development and understanding trajectories of resiliency after extreme prematurity. Pediatrics. 2009; 124(1):387-390

36. Hack M, Cartar L, Schluchter M, Klein N, Forrest CB. Self-perceived health, functioning and well-being of very low birth weight infants at age 20 years. $J$ Pediatr. 2007;151 (6):635-641, 641, e1-e2

37. Kajantie E, Strang-Karlsson S, Hovi P, et al. Adults born at very low birth weight exercise less than their peers born at term. J Pediatr. 2010;157(4):610-616, 616, e1

38. Rogers M, Fay TB, Whitfield MF, Tomlinson J, Grunau RE. Aerobic capacity, strength, flexibility, and activity level in unimpaired extremely low birth weight ( $<0 r=800$ g) survivors at 17 years of age compared with term-born control subjects. Pediatrics. 2005;
116(1). Available at: www.pediatrics.org/cgi/ content/full/116/1/e58

39. Smith LJ, van Asperen PP, McKay KO, Selvadurai $H$, Fitzgerald DA. Reduced exercise capacity in children born very preterm. Pediatrics. 2008;122(2). Available at: www.pediatrics. org/cgi/content/full/122/2/e287

40. Starfield B, Riley AW, Witt WP, Robertson J. Social class gradients in health during adolescence. J Epidemiol Community Health. 2002;56(5):354-361

41. Newacheck PW, Hung YY, Park MJ, Brindis CD, Irwin CE Jr. Disparities in adolescent health and health care: does socioeconomic status matter? Health Serv Res. 2003;38(5):1235-1252

42. Sallis JF, Zakarian JM, Hovell MF, Hofstetter CR. Ethnic, socioeconomic, and sex differences in physical activity among adolescents. J Clin Epidemiol. 1996;49(2):125-134

43. Corder K, van Sluijs EMF, Goodyer I, et al. Physical activity awareness of British adolescents. Arch Pediatr Adolesc Med. 2011; 165(7):603-609

44. DiClemente RJ, Sales JM, Danner F, Crosby RA. Association between sexually transmitted diseases and young adults' selfreported abstinence. Pediatrics. 2011;127 (2):208-213

45. Dolan P. The effect of experience of illness on health state valuations. J Clin Epidemiol. 1996;49(5):551-564

46. Waters E, Stewart-Brown S, Fitzpatrick R. Agreement between adolescent self-report and parent reports of health and wellbeing: results of an epidemiological study. Child Care Health Dev. 2003;29(6):501-509

47. Upton P, Lawford J, Eiser C. Parent-child agreement across child health-related quality of life instruments: a review of the literature. Qual Life Res. 2008;17(6):895-913

48. World Health Organization. Towards a Common Language for Functioning, Disability and Health. ICF. Geneva, Switzerland: World Health Organization; 2002

49. Luciana M. Cognitive development in children born preterm: implications for theories of brain plasticity following early injury. Dev Psychopathol. 2003;15(4):10171047

50. Shedler J, Block J. Adolescent drug use and psychological health. A longitudinal inquiry. Am Psychol. 1990;45(5):612-630

51. Park MJ, Adams SH, Irwin CE. Health care services and the transition to young adulthood: challenges and opportunities. Acad Pediatr. 2011;11(2):115-122 